\title{
OS VelHOS MARINHEIROS, DE JoRGE AMADO E 0 VELHO E O MAR, DE HEMINGWAY: NARRATIVAS SIMBÓLIICAS DO MAR
}

http://dx.doi.org/10.11606/issn.2237-1184.v0i24p10-26

Jairo Nogueira Luna

Universidade de Pernambuco (UPE)

RESUMO

Neste artigo, buscamos apresentar um trabalho de literatura comparada entre as obras Os Velhos Marinheiros, de Jorge Amado (1961 - traduzido para o inglês por Harriet de Onis, Home is the Sailor) e O Velho e o Mar, de Ernest Hemingway (1951 - do original em inglês, The Old Man and the Sea, traduzido por Jorge de Sena). Destacamos na obra de Hemingway a questão das dicotomias e as interpretações simbólicas que envolvem Santiago e o peixe. Em Os Velhos Marinheiros demonstramos os aspectos relativos às narrativas fantasiosas de Vasco Moscoso. Em ambas as obras buscamos demonstrar a importância da hipérbole como recurso que define aspectos importantes dos dois enredos. Ainda, tentamos definir alguns aspectos relativos ao uso da ironia e do sentido trágico em Hemingway e tragicômico em Jorge Amado.

\section{ABSTRACT}

In this article, we seek to present a work of literature compared between the works Home is the Sailor (translation of Os Velhos Marinheiros), Jorge Amado (1961) and The Old Man and the Sea, Ernest Hemingway (1951, translated to portuguese: O Velho e o Mar, by Jorge de Sena). We highlight the work of Hemingway the issue of dichotomies and symbolic interpretations, involving Santiago and the fish. In The Old Sailors demonstrated the aspects of the fantastic tales of Vasco Moscoso. In both works we demonstrate the importance of hyperbole as a resource that defines important aspects of the two plots. Still, we try to define some aspects concerning the use of irony and tragic sense Hemingway and tragicomic in Jorge Amado.
PALAVRAS-CHAVE:

Ernest Hemingway.

Jorge Amado.

Simbologia.

Dicotomias.

Hipérboles.

Neo-estruturalismo.

Semiótico.

\section{KEYWORDS:}

Ernest Hemingway.

Jorge Amado, symbology.

Dichotomies.

Hyperbole.

Neo-structuralist.

Semiotics. 


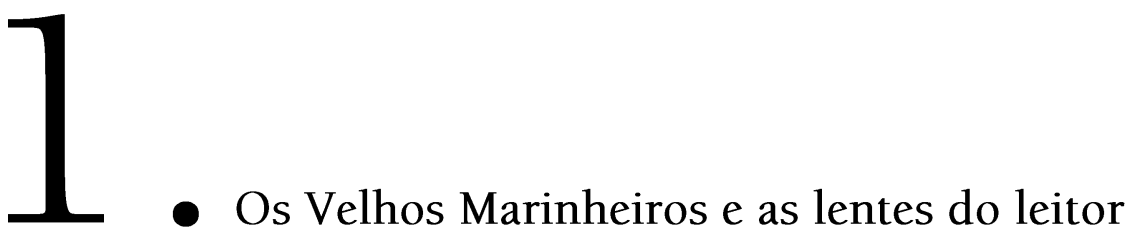

O romance Os Velhos Marinheiros, ou O Capitão-de-Longo-Curso, publicado em 1961, é um volume com duas histórias. A da Morte e a Morte de Quincas Berro d'Água e a do Capitão-de-Longo-Curso, propriamente dita. A narrativa da suposta vida de marinheiro, capitão de navio, de Vasco Moscoso de Aragão é rica de significados quando entramos na discussão sobre a questão que envolve a veracidade, a ficção e a verossimilhança. Vasco Moscoso, que já tem no primeiro nome a referência ao mais conhecido navegante português, chega à cidadezinha litorânea de Periperi vestido com a farda da marinha mercante, começa a espalhar suas narrativas sobre os vários portos do mundo que conheceu e sobre as aventuras que viveu no mar. A polêmica se instala quando algumas pessoas do lugar, incomodadas com seus relatos buscam saber do quanto são verídicos. Chico Pacheco foi a Salvador pesquisar sobre a vida do capitão e traz uma outra versão, de tratar-se dum homem que viveu nos bordéis da cidade, onde gastara a fortuna deixada por um avô português. O final do romance coloca em prova definitiva as habilidades de homem do mar de Vasco Moscoso de Aragão.

Massaud Moisés observa que nesta obra Jorge Amado: "a odisséia de Vasco Moscoso de Aragão, é uma novela enxuta, sem as hipérboles que dilatam artificialmente o enredo" (MOISÉS, 1996) ${ }^{1}$ e mais um pouco adiante, comparando esta obra com Gabriela Cravo e Canela, comenta: "Os dois textos acusam as vertentes principais do autor: fácil vinculá-las por um nexo de contiguidade; se, porém, tomamos uma a uma, verificaremos que tanto se ajustam ao molde da novela como poderiam destacar-se, originando uma série de contos." (MOISÉS, 1996)2.

Podemos tentar encontrar o limite que se torna difuso nas narrativas de Vasco Moscoso, partindo do bom senso e de uma lógica cotidiana na busca entre a veracidade e a ficção quando se trata de descobrir a exequibilidade ou a

\footnotetext{
${ }^{1}$ MOISÉS, Massaud. História da Literatura Brasileira - O Modernismo. São Paulo, Cultrix, 1996. p.209

2 Op.cit., p. 209.
} 
coerência acerca dos fatos pretéritos, mas a busca de uma tentativa de exatidão fronteiriça entre ambos é no mínimo uma ilusão metodológica.

Uma das grandes qualidades de Os velhos marinheiros é que esse romance se afasta dos caminhos retos do naturalismo - mesmo do neonaturalismo de cunho socioeconômico, que o próprio Jorge Amado chegou a cultivar. O toque de humor filtrado através das digressões de seu narrador tem a propriedade de trazer ao leitor - ao contrário do que quer esse narrador/historiador ("ingênuo", para usar o termo de Le Goff) — dúvidas e incertezas. As hesitações desse personagem, enunciador de um discurso literário que se quer histórico, conduzem inapelavelmente a questões capitais que dizem respeito à historiografia e a conceitos como 'verdade', 'fidelidade', 'fontes'. (DIAS, 2005)3

Vasco Moscoso de Aragão tem uma forma de narrar muito peculiar, mas ao mesmo tempo, muita arquetípica da figura de um velho marinheiro, conhecedor de muitos lugares e situações ao mar. Suas frases são de orações curtas, que se seguem num contínuo processo aglutinador, como se fosse buscando na memória algum detalhe, alguma coisa de importante que desse sentido ao fato narrado, aliás, não apenas dar sentido ao fato narrado, mas que esse fato narrado tenha sentido em se encaixar em algum evento do presente. Vasco encaixa suas histórias a partir de situações do presente. Por exemplo, no episódio em que se apresenta o velório da velha Doninha Barata reinava o silêncio e um certo tom mórbido:

Era um velório sonolento e silencioso. Cada um pensava em si próprio, via-se estendido num caixão, entre velas de mau olor, flores aos pés, para sempre terminado. Por vezes um ou outro estremecia, o medo estava cravado em cada um deles, o medo da morte. (AMADO, 1979)

O silêncio costumeiro daquela localidade quando em velórios é quebrado pela expressão de Vasco ao observar a defunta: "Vê-se que quando moça foi uma bela mulher...", o que causa uma certa surpresa nas pessoas e Vasco como de costume, se apresentava: "Vestido com seu paletó de sarja azul com botões metálicos, o cachimbo e o boné". E então, em determinado momento começa a narrar a história da dançarina Soraia, dos marinheiros Johann e Giuseppe, como se fosse um contínuo rememorar, quase num processo narrativo semelhante à rapsódia.

Quem muito viveu é assim: qualquer fato, paisagem ou face recorda-lhe algo do passado, uma história de amor, as margens de um rio, o rosto de alguém. Não

\footnotetext{
${ }^{3}$ DIAS, Márcio Roberto Soares. "A Vez da Subjetividade No Leme da História: Discurso Historiográfico e Ficção em Os Velhos Marinheiros." in: Revista Alpha, publicação da UNIPAM. Patos de Minas, MG, n. ${ }^{\circ}$ 6, p. 265-272, 2005. p. 270. Disponível em: http://alpha.unipam.edu.br/documents/18125/19714/a-vez.pdf

${ }^{4}$ AMADO, Jorge. Os Velhos Marinheiros. São Paulo: Círculo do Livro, 1979. p. 45
} 
enxergara o comandante no rosto encarquilhado e macilento de Doninha, onde os outros viam apenas a morte, a face trigueira e os longos cabelos azulados de Soraia, a pecadora, a mórbida bailarina de lábios de fogo? (AMADO, 1979) ${ }^{5}$.

As memórias de personagens femininas são de destaque no discurso de Vasco, seja porque se sinta, talvez, de fato o capitão que alega ter sido, seja porque se aproximam da sua vivência em bordéis, como denuncia seu delator, Pacheco. Entre as personagens femininas citadas, ganha destaque a de Dorothy.

Dorothy, por sua vez, do romance em estudo, à luz do Capitão Vasco Moscoso de Aragão, ganha nuances contraditórias, pois, nem de longe, reflete o que realmente era; colocando por terra o conceito de Verdade, em que se respalda a narrativa da hegemonia. Esta, pobre e prostituta, portava o perfil de mulher pública, não assumindo comprometimentos amorosos, sendo discriminada e repreendida, devido à sua liberdade sexual. (VIANA, 2010) ${ }^{6}$

Desde seu primeiro encontro com Dorothy, Vasco se apresenta como um homem que tenta se colocar como lutando para manter sua posição de marinheiro conquistador de mulheres, porém, no caso de Dorothy, a narrativa de Vasco é cheia de surpresas, nesse sentido, demonstrando ser um marinheiro atordoado pelos sentimentos de paixão:

No primeiro porto, Makassar, perdido e sujo porto do extremo-oriente, despediu-se da tripulação. Choraram velhos marujos de rosto curtido, ao apertarem-lhe a mão leal. Havia marcado um encontro com Dorothy na casa de uma certa Carol, contrabandista de ópio, a quem tivera ocasião de fazer um favor. Inutilmente o marido a esperara, seguiu viagem sozinho. Foram duas semanas de delírio, escondidos numa pequena casa nos confins da cidade, em plena selva tropical, entregues ao seu amor numa fúria de danados, como se adivinhassem... [grifos nossos] (AMADO, 1979) ${ }^{7}$.

Notemos nesse trecho as qualificações que são dadas aos personagens, lugares e objetos da cena. O porto, os marujos, a mão de Vasco, Carol, a casa, a selva e o amor. São adjetivações e descrições que buscam criar um cenário de submundo, underground, de marginalização com o fim de demonstrar sua vida de giramundo desafiador de padrões previsíveis.

Notemos ainda como os períodos se ligam apenas por aproximação, não existem conjunções que determinam um domínio da subordinação. Antes, pelo contrário, as frases parecem se suceder como imagens que se completam, mas autônomas em si mesmas. Jean Roche, professor e historiador francês, fez um

\footnotetext{
${ }^{5}$ Op.cit., p. $46-47$

${ }^{6}$ VIANA, Kaleandra do Nascimento. "A visão contra-hegemônica através da personagem Dorothy na narrativa Os Velhos Marinheiros de Jorge Amada" In: Revista Urutágua, n. 22, set/dez, 2010, p. 75-83. Citação da página 78.

${ }^{7}$ Op.cit., p. 51
} 
interessante estudo - de caráter estruturalista na essência - da obra de Jorge Amado traçando vários quadros comparativos e quantitativos acerca das características estilísticas e gramaticais do escritor baiano. Dividiu a obra de Amado em dois grupos, um anterior ao seu exílio e outro posterior. Notou diferenças substanciais no estilo do autor entre estes dois grupos, no que se refere, p.ex., ao uso de orações subordinadas e coordenadas e de períodos compostos uma modificação significativa:

Com efeito, a porcentagem de orações subordinadas em relação ao número total de orações (21,5 por cento) evolui dentro de limites mais estreitos (de 11 a 32 por cento) e paralelamente à porcentagem de períodos compostos, com a particularidade de ter seu valor máximo em Jubiabá e seu mínimo em Velhos Marinheiros e Tenda - o máximo no primeiro período e o mínimo em pleno segundo período da obra amadiana. (ROCHE, Jean. 1988) ${ }^{8}$

Voltando a falar das personagens femininas que têm papel de destaque nas narrativas do velho capitão, principalmente a sempre lembrada saudosamente Dorothy. O primeiro episódio da aparição da personagem Dorothy está ligado ao caso do telescópio, instrumento que causa curiosidade ("aumenta a Lua 80 vezes!"), e da possibilidade que ele apresenta de se observar a realidade com mais detalhe. Nada mais metafórico e ao mesmo tempo antípoda da narrativa de Os Velhos Marinheiros, em que a realidade se afasta cada vez que se tenta aproximar dela para verificar-se sua veracidade.

Jorge Amado defende em Os velhos marinheiros a primazia da imaginação sobre a razão, das utopias pessoais sobre os fatos históricos, da ficção sobre o real, da palavra poética sobre o rigor conceitual. O capítulo intitulado 'Do telescópio e do seu variado uso, com Dorothy ao luar no tombadilho' traz elementos que ilustram simbolicamente o poder e o alcance dos princípios que regem a vida do Capitão Vasco Moscoso: 'Ah! O telescópio... Nele partiam para a aventura da Lua e das estrelas, para fantásticas viagens, rompiam as fronteiras da monotonia e do tédio. [...]' (AMADO, 1981, p. 38-40). (PEREIRA \& PEREIRA, 2007) ${ }^{9}$

Após as controvérsias criadas por Pacheco, o capitão Vasco se vê ante a inusitada obrigação de ter que levar um barco a navegar pelo litoral do Nordeste, após a morte do capitão original do navio. Enfrentando desafios inerentes à navegação, Vasco leva o barco a lugares como Recife, Natal, Fortaleza e Belém. $\mathrm{Na}$ tripulação conhece Clotilde, com quem inicia um romance ao ponto de jurarem casamento. Clotilde fica sabendo do grande amor do passado do capitão, Dorothy. Na cena da jura de amor, podemos destacar alguns aspectos

\footnotetext{
${ }^{8}$ ROCHE, Jean. Jorge Bem/Mal Amado. São Paulo: Clube do Livro, 1988. p. 130.

9 PEREIRA, Rubens Edson Alves \& PEREIRA, Elvya Shirley Ribeiro. "Enredos de Jorge Amado em suas navegações de cabotagem" in: Letras de Hoje, Porto Alegre, v, 48, n. ${ }^{\circ}$ 4, set/dez, 2013, p. 501-511. Citação da página 507.
} 
da narração:

$\mathrm{Na}$ noite de luar vogava o navio, céu e mar banhados de prata e ouro. $\mathrm{Na}$ coberta, juntos à amurada, o Comandante e Clotilde trocavam juras de amor. Riam sem motivo, suspiravam, diziam palavras inconseqüentes, roubavam-se beijos, apertavam-se as mãos. Até ouvirem ruído na escada e buscarem abrigo na sombra do barco de salvamento. Na coberta apareceu outro casal. Primeiro viram o vulto do Dr. Firmino Morais, o advogado paraense. Espiou em redor, terminou de subir, fez um sinal, chamando. Surgiu então, de mãos estendidas para ele, Moema, a mameluca, e ali mesmo se abraçaram e se beijaram numa fúria e pressa de danados.

- Descarada... - murmurou Clotilde. - Ele é casado...

- O amor — respondeu-lhe o Comandante — não respeita convenções, o amor é como a tempestade.

Tomou-lhe da mão, saíram pelo outro lado, foram-se juntar com os passageiros no salão. Clotilde pedira-lhe segredo sobre o compromisso jurado ao luar. Queria casar-se sem convidados, sem notícias, sem festa, apenas ela, Vasco, seu irmão, sua cunhada. E, se tivesse de ser, deveriam fazê-lo em tempo breve, não aceitava noivado a demorar-se... [grifos nossos] - (AMADO, 1979) ${ }^{10}$.

No início desta cena, Jorge Amado utiliza dois pares de dicotomias (céu / mar; prata / ouro) para a seguir apresentar "o comandante e Clotilde" sob a luz da lua. Lua e luar têm uma relação de contiguidade, de metonímia em oposição às dicotomias; desse modo, "as juras de amor" surgem como que decorrentes da transformação do par Vasco / Clotilde, não mais como separados, antagônicos, mas agora unidos, contíguos em sentimento e pensamento. Daí que "beijos" e "mãos" assumem também a condição de metonímias desses corpos que se unem. O ruído vem quebrar essa busca de unificação - notemos então a relação entre as palavras "abrigo" e "salvamento". O ruído era causado por outro "casal", o que conforma o ruído ao âmbito paralelo de Vasco / Clotilde: o masculino e o feminino. Voltando às duas dicotomias do início da cena, se a primeira é formada por duas palavras de gênero masculino, a segunda não, prata e ouro se ajustam ao par masculino / feminino. O casal que surge é revelado aos poucos: Primeiro o masculino, o vulto do Dr. Firmino de Moraes. E a chegada da personagem feminina se faz por uma sequência marcada pela técnica cinematográfica, ao modo da montagem eisensteniana. Os gestos do advogado, teatrais: "Espiou em redor, terminou de subir, fez um sinal, chamando." Então aparece metonimicamente as mãos da personagem feminina. E a revelação de sua identidade se faz com o apoio de uma figura sonora, a aliteração, que se associa em termos fonéticos às "mãos": "Moema, a mameluca, e ali mesmo..." Após a observação de Clotilde de que o advogado é casado, julgando assim Moema como uma "descarada", o capitão apresenta uma justificativa para a ação

${ }^{10}$ Op.Cit., p. 150

15 | E N S A I O S 
da moça, definindo um aspecto do amor: "O amor não respeita convenções", e a seguir apresenta uma comparação: "O amor é como a Tempestade". Comparação romântica ao modo do romantismo alemão, diríamos (Sturn und Drang). Passamos agora das mãos de Moema, a mameluca; para as mãos de Clotilde - um travelling em close-up dos mais criativos dum cinema impressionista. E a amada do capitão, pede-lhe "segredo" sob o pacto de amor que juraram e o pedido de casamento. O segredo envolve assim a relação amorosa de ambos ao âmbito do que deve ser oculto, do mistério, na tonalidade das proibições, como foi o encontro de Firmino e Moema. A justificativa para o segredo é que Clotilde queria casar "sem convidados, sem notícias, sem festa", como se expressasse o desejo de despir-se das convenções sociais, afinal o casamento é um dos momentos mais festivos destas convenções.

Podemos observar, pela análise dessa cena, como a escrita em Os Velhos Marinheiros segue um planejamento de movimentos, de falas, de imagens, cuja organização maior é a transformação da capacidade de observação do leitor na busca de encontrar a verdade acerca da figura de Vasco Moscoso de Aragão. Agora, o leitor é que está metaforicamente munido daquele telescópio, com suas lentes, a passear, levado pelo narrador e pela personagem Vasco, a se orientar pelos detalhes, pelos interstícios do discurso narrativo.

As dicotomias se ajustam num processo macrocósmico maior, o da antítese entre realidade e ficção. Esta antítese vai sendo aos poucos construída até o momento em que Vasco Moscoso assume o comando do navio, a partir daí, vai se desconstruindo a oposição antitética por uma simbiose, em que a ficção (as habilidades marítimas de Vasco, inexistentes de fato) vão se sobrepondo até o momento em que o acaso (a tempestade em Belém) o leva a ser reconhecido pela sociedade como um grande comandante. A antítese terra / mar assim se apresenta também como análoga da relação entre realidade e ficção. É no mar que está a imagem criada de Vasco para si mesmo. O mar é a metáfora de sua imaginação, de suas aventuras inventadas. Fluído, fugidio, inconstante ante às intempéries, vago e surpreendente. A terra, firme, segura, é a metáfora da realidade que ele não aceita e nega continuamente a cada aventura inventada. Quando se vê forçado a enfrentar o mar como comandante de um navio, agarra-se ao improviso de cada situação, como se acreditasse que pudesse manter para si e para os outros a imagem que construíra. Em momento algum, no romance, vemos Vasco duvidar de sua capacidade de reconstrução da realidade por meio da sobreposição da ficção sobre ela. Por fim, são os amores que lhe escapam ao domínio capitaneado. Dorothy, Clotilde são figuras femininas que apenas parecem se sujeitar por um certo tempo ao seu comando, mas fogem no instante decisivo, se libertam e seguem caminhos diferentes. As mulheres de Vasco são metáforas do mar. Notemos a primeira cena em que 
Vasco Moscoso vê Clotilde:

Demorou ainda alguns minutos, porém. Porque, perfumada, os cabelos em cachos cuja perfeição custara-lhe com certeza grande parte da tarde, vestido majestoso, um xale de seda na mão, aqueles olhos de quem conduzia secreto desgosto, e sem o pequinês (detalhe alvissareiro), vinha deslizando Clotilde pelo convés. Pulou mais forte o coração do comandante. Ela já o enxergara e atiravalhe um adeusinho que era ao mesmo tempo um chamado. Aproximou-se. —É uma deusa do mar... (AMADO, 1979) $)^{11}$

Comparemos com a cena em que Vasco Moscoso narra sobre a tensão amorosa entre ele e Dorothy:

Algum dos senhores já tentou convencer uma mulher, fazê-la compreender a mais clara das situações? Dorothy, ainda mais apaixonada que ele, necessitando dele, disposta a suicidar-se, a atirar-se no mar, se ele não a quisesse, chegou ao cúmulo de certa madrugada, em trajes de dormir, subir ao tombadilho reservado aos oficiais e chamar na porta de sua cabine. Vestida com a camisola de noite, vaporosa, toda em rendas, mal-escondendo a carne ansiosa, Dorothy, os pés descalços, corria entre eles pela sala, Adriano Meira passava a língua nos lábios. $(A M A D O, 1979)^{12}$

Clotilde é definida por Vasco Moscoso como uma "deusa do mar". Tétis, esposa de Oceano? Anfitrite, esposa de Poseidon? Clotilde faz por utilizar seus artifícios para encantar o comandante ("os cabelos em cachos...custara-lhe grande parte da tarde"). Por sua vez, Dorothy, dominada pela paixão, imprevisível como o próprio mar, está "disposta a suicidar-se, a atirar-se no mar". Nova Moema? Aliás é Moema, a mameluca, a mulher que finalmente parece compreender e aceitar as dicotomias que definem Vasco Moscoso:

Como vêem, já novamente torna-se difícil distinguir a verdade, despi-la dos véus da fantasia. Afinal, a quem amara o Comandante, a quem se declarara na noite da grande lua, na coberta? A Clotilde, a Grande Baqueana, madura e com chiliques, ou à agreste e impudica Moema, cuja mão amparara seu braço na hora difícil, a mameluca com urgência de chegar a seu dramático destino? Quanto a mim, não sei e desisto de saber. (AMADO, 1979)13

Neste trecho, o narrador nos confessa a impossibilidade de separar a verdade (realidade) da fantasia (ficção). Vasco só pode ser definido por sua capacidade de misturar ambas as coisas, de viver com intensidade tal suas fantasias, como um Dom Quixote, a ponto de conseguir transfigurar-se num

\footnotetext{
${ }^{11}$ Op.cit., p. 123

${ }^{12}$ Op.cit., p. 51

${ }^{13}$ Op.cit., p. 164
} 
comandante de navio. Esta intensidade que Vasco aplica aos seus sentimentos e às suas aventuras é a hipérbole que contorna as antíteses terra / mar, realidade / ficção. São antíteses grandiosas, hiperbólicas. Assim, a inconstância do mar, marcada pela antítese tempestade / calmaria é que vai colocar, seja pelo destino, seja pela noção de acaso, a solução dos impasses que tais antíteses compõem.

Jorge Amado trabalha o tema do mar em várias outras obras, sempre com um sentido simbólico, ora como metáfora, ora como hipérbole das condições humanas e como analogia da vida. Mar Morto (1936), contando a vida de pescadores, com destaque para o lendário Guma ${ }^{14}$; ou ainda em A Morte a Morte de Quincas Berro d'Água (1959), em que a morte derradeira do já morto Quincas se dá no mar, além da analogia entre a embriaguez e a náusea ou o enjôo em alto $\operatorname{mar}^{15}$; ou ainda no quase-livro-de-memórias Navegação de Cabotagem (1992), com o subtítulo de "apontamentos para um livro de memórias que jamais escreverei" Talvez Mar Morto fosse a obra que mais se aproxima em termos de enredo e de características ao livro O Velho e o Mar, de Hemingway. Mas neste texto não buscamos a confirmação da proximidade entre ambos os autores, mas os modos peculiares e simbólicos com que trataram do mar.

\section{O Velho e o Mar: O Peixe Metonímico e Metafórico}

O livro O Velho e O Mar'16 (The Old Man and the Sea, 1951), de Ernest Hemingway é um dos livros mais conhecidos de literatura norte-americana no Brasil. Adaptado para o cinema em 1958, com direção de John Sturges e Spencer Tracy no papel do velho pescador Santiago.

É a história do velho pescador, desacreditado em sua aldeia, que se lança ao mar em busca da pesca derradeira e consegue pescar um descomunal peixe espada que, no entanto, acaba sendo devorado por tubarões e só resta ao velho os ossos. Narrativa cheia de simbologias, notadamente as que se referem a figura de Cristo. A significação simbólica do peixe assim como a dos atos de Santiago permite uma ambiguidade na definição dos papéis simbólicos:

Quem lê o livro com atenção percebe que o peixe, segundo os

\footnotetext{
${ }^{14}$ Sobre a importância da obra e vários aspectos interpretativos indicamos a leitura de Colóquio 70 Anos de Mar Morto. Edição da Fundação Casa Jorge Amado, 2008. Vários Autores. O livro contém textos apresentados no colóquio que se realizou na Fundação Casa Jorge Amado, Salvador, nos dias 28, 29 e 30 de agosto de 2006.

${ }^{15}$ Indicamos a leitura de GROISMAN, Judith. "Gritos e Sussuros em A Morte e a morte de Quincas Berro d'água". UFB, Ensaios sobre o escritor, 1982. Também, de TAVARES, Ildázio. Quincas Berro D’água: O Santo Picaresco. UFB, Ensaios sobre o escritor, 1982. Ou ainda, o trabalho de NEMRAVA, Daniel. O Carnavalesco e o Mítico na Morte de Quincas Berro d'Água. Universidade Masaryk / Universidade Palcky, Brno / Omoluc - Rep. Tcheca, 2000. Disponível em: http://www.premioiberoamericano.cz/documentos/6taedicion/2doPremioVI DanielNemrava.pdf

16 Tanto para comparação da nossa tradução, algo livre, com uma tradução editada; ou ainda, para fins de análise se a tradução em português não alterou o texto original, nos valemos da edição em português traduzida por Jorge de Sena. HEMINGWAY, Ernest. O Velho e o Mar. Tradução Jorge de Sena. Disponível em BaixeLivros: http://www.baixelivros.biz/baixar-livro-o-velho-e-o-mar-ernest-hemingway-pdf-epub-mobi//
} 
pensamentos de Santiago, é o irmão que ele matou: 'But I have killed this fish which is my brother (...)'. Matando o peixe, ele, de certo modo, se mata também. Esta leitura pode levar o leitor a considerar mais uma teoria radicalmente oposta à que foi levantada antes, no sentido de que o peixe, e não Santiago, é o símbolo de Cristo. (NAZARIO, $1988)^{17}$

Vários índices podem ser levantados para se justificar uma interpretação simbólica que associa Santiago a Cristo, ou no outro sentido, de que o peixe é que seria Cristo; como as sete quedas de Santiago ao chegar ao porto ou o fato do peixe ser no início o signo que representava o Cristianismo.

The first to come on mind can be the following: the old man's failure is known to the community, and although all behave to him with a respect, he feels that he loses his credit. His fight for a big fish can mean a fight for his weakening craft and body abilities. The big fish could show to himself and to others that he can still keep up with the pace of life. Man would demonstrate himself as a worthy member of the society he lives in - the fish would present both the perseveration of man's social status and his incessant life powers. (MARAKOVA, 2011) $)^{18}$

Nesse sentido, podemos entender o livro de Hemingway como uma alegoria, uma vez que os aspectos simbólicos buscam colocar em evidência de forma concreta no peixe, no barco, no pescador, nos tubarões representações de elementos abstratos como humildade, vontade, perseverança, castigo, remissão e vitória. Como observa Michaell Hollister:

The Old Man and the Sea is an allegory of human aspiration in general, idealistic pursuit dramatizing the theme of attaining a spiritual victory that transcends destruction, the major theme of religions and of "The Artist of the Beautiful" by Hawthorne, in which the artist's butterfly is destroyed. In "The Butterfly and the Tank" (1938) Hemingway embodies the polarity of destruction and transcendence. (HOLLISTER, 2012, p. 7) $)^{19}$

Consideremos alguns aspectos relativos à linguagem da obra, notadamente à questão da pesca do peixe-espada (marlim) e do mar.

It was getting into the afternoon and the boat still moved slowly and steadily. But there was an added drag now from the easterly breeze and the old man rode gently with the

\footnotetext{
${ }^{17}$ NAZARIO, Julian. Ernest Hemingway. São Paulo: Ática, série Princípios, vol. 139, 1988. p.63

${ }^{18}$ MARAKOVA, Lenka. The Interpretation of Hemingway's The Old Man and the Sea (Literary Psichological-analysis). Brno, Rep. Checa, Univ. Masaryk, dissert. de mestrado, orientador: Pavlá Buchtová, 2011. p. 23-24

${ }^{19}$ HOLLISTER, Michael. "Analysis: The Old Man and the Sea". Disponível em: http://www.amerlit.com/novels/ANALYSIS Hemingway, Ernest The Old Man and the Sea (1952) analysis in detail.pdf p. 7.
} 
small sea and the hurt of the cord across his back came to him easily and smoothly.

Once in the afternoon the line started to rise again. But the fish only continued to swim at a slightly higher level. The sun was on the old man's left arm and shoulder and on his back. So he knew the fish had turned east of north.

Now that he had seen him once, he could picture the fish swimming in the water with his purple pectoral fins set wide as wings and the great erect tail slicing through the dark. I wonder how much he sees at that depth, the old man thought. His eye is huge and a horse, with much less eye, can see in the dark. Once I could see quite well in the dark. Not in the absolute dark. But almost as a cat sees.

The sun and his steady movement of his fingers had uncramped his left hand now completely and he began to shift more of the strain to it and he shrugged the muscles of his back to shift the hurt of the cord a little. (HEMINGWAY, 1951, p. 66-67)20

Notemos como a relação entre céu e mar se constrói, secundada pelas dicotomias de caráter antitéticos, superfície visível / profundidade invisível, visão / não visão, movimento / inércia, oeste / norte, juventude / velhice. Quando lemos "It was into the afternoon", o conhecimento de que era tarde só é possível a Santiago pela observação da posição do Sol (visão), e quando "the boat moved slowly and steadily" temos a quebra do estágio parado (inércia) pelo movimento, mas por extensão, o barco só poderia ter se movimentado assim se o peixe, invisível por estar na profundidade o puxasse. Quando o barco muda de direção do oeste para o norte (90 graus, portanto), tal mudança de direção só é possível novamente pela expressão do invisível no visível (o peixe agindo sobre o barco). Quando Santiago imagina o peixe a nadar nas profundezas e compara suas barbatanas com asas, temos a metáfora do céu transubstanciado na água e enquanto os pássaros voam ao dia sob a luz do Sol, o peixe vai cortando a escuridão. Daí Santiago transfere a relação luz / escuridão para a dicotomia presente / passado, na qual, no passado podia enxergar no escuro como um gato, e no presente mal enxerga na própria luz. O movimento do Sol transfere luz e energia para seus músculos, na busca de desentranhar das profundezas, da escuridão, do invisível o peixe para o lado visível do mundo. Por sua vez, o leitor também acompanha atento essas movimentações do barco, esperando também ter na próxima frase a imagem do peixe e a conquista de Santiago, co-participa com o velho da sua busca.

\section{Um Olhar Neo-estruturalista Semiótico para a representação do Mar}

Denominamos esta parte com referência ao "Neo-estruturalismo

20 HEMINGWAY, Ernst. The Old Man and the Sea. 1951, 1. ${ }^{a}$ ed. Edição Lelivros, s.d. Disponível em: http://ebookbees.com/the-old-man-and-the-sea-free-ebook/ p. 66-67 
Semiótico", no sentido de que buscaremos analisar aspectos da linguagem de ambas as obras na busca de encontrar elementos simbólicos que determinam caracteres marcantes das mesmas e de como esses símbolos tem aspectos ligados às sociedades que são ali representadas.

O mar é mais do que um cenário tanto em Os Velhos Marinheiros quanto em $O$ Velho e o Mar. Se bem que na obra de Jorge Amado o mar só assuma a condição de co-partícipe do protagonismo ao final. Nessas obras o mar assume não raras vezes uma condição metafórica e simbólica. É espaço da realização da aventura, e o elemento da natureza que se interpõe ao protagonista como o limite de suas possibilidades. Em $O$ Velho e o Mar de Hemingway, o mar determina a relação entre visível e invisível, entre luz / escuridão, entre passado / presente, movimento / inércia e por fim, todas estas dicotomias se dirigem para a simbologia de duplas dicotômicas Santiago-peixe / homem-Cristo; em que existe uma completa inter-relação entre os dois pares: Santigo-homem, SantigoCristo; peixe-homem e peixe-Cristo. A conquista do marlim e a derrota ante os tubarões - estes claramente simbolizando, a nosso ver, os outros homens que se impõem para a consciência de Santiago a necessidade de recuperar sua credibilidade, sua força vital e seu respeito na comunidade.

The sun was rising for the third time since he had put to sea when the fish started to circle. He could not see by the slant of the line that the fish was circling. It was too early for that. He just felt a faint slackening of the pressure of the line and he commenced to pull on it gently with his right hand. It tightened, as always, but just when he reached the point where it would break, line began to come in. He slipped his shoulders and head from under the line and began to pull in line steadily and gently. He used both of his hands in a swinging motion and tried to do the pulling as much as he could with his body and his legs. His old legs and shoulders pivoted with the swinging of the pulling.

"It is a very big circle," he said. "But he is circling." Then the line would not come in any more and he held it until he saw the drops jumping from it in the sun. Then it started out and the old man knelt down and let it go grudgingly back into the dark water.

"He is making the far part of his circle now," he said. I must hold all I can, he thought. The strain will shorten his circle each time. Perhaps in an hour I will see him. Now I must convince him and then I must kill him. But the fish kept on circling slowly and the old man was wet with sweat and tired deep into his bones two hours later. But the circles were much shorter now and from the way the line slanted he could tell the fish had risen steadily while he swam.

For an hour the old man had been seeing black spots before his eyes and the sweat salted his eyes and salted the cut over his eye and on his forehead. He was not afraid of the black spots. They were normal at the tension that he was pulling on the line. Twice, though, he had felt faint and dizzy and that had worried him.

"I could not fail myself and die on a fish like this," he said. "Now that I have him coming só beautifully, God help me endure. I'll say a hundred Our Fathers and a hundred Hail Marys. But I cannot say them now. Consider them said, he thought. I'll say 
them later. [grifos nossos] (HEMINGWAY, 1951) ${ }^{21}$

Hemingway começa este trecho marcando o tempo de forma indireta, não diz que era o terceiro dia, mas que era a terceira vez que o sol nascia: uma forma de aproximar a situação do pescador para o âmbito mais tribal, mais rústico; Santiago é um homem solitário ao mar, sem relógio, sem calendários; próximo está de Ismael/Ahab de Moby Dick, de Herman Melville (1851), próximo está de Robison Crusoé, de Daniel Defoe (1719). A relação visível / invisível se estabelece a partir da narração dos movimentos da linha. Santiago não vê o peixe, apenas percebe seus movimentos, que traduz a partir do comportamento da linha. Quando se narra que Santiago "saw the drops jumping from it in the sun", o close-up dado, o detalhe que se apresenta é mais do que um simples recurso estilístico. O Sol que ilumina as gotas d'água, marcando o limite do visível; abaixo, nas águas oceânicas está o desejado peixe, invisível, apenas compreendido pelos efeitos que produz sobre a linha, as gotas d'água que caem da linha pelo movimento causado: metonímia sintética.

O traçado do círculo é a metáfora do relógio que Santiago não tem. Observa o movimento do Sol para estabelecer em qual parte do dia está (manhã, tarde, anoitecer); mas ali, naquele momento, os movimentos circulares do peixe determinam maior precisão ("in an hour"). Os movimentos circulares do peixe se transformam em metáfora dos movimentos dos ponteiros dos relógios: "But the fish kept on circling slowly and the old man was wet with sweat and tired deep into his bones two hours later.", e ainda: "For an hour the old man had been seeing black spots...".

Por fim, ao expressar sua fé - poderia rezar uma centena de pai-nosso e outro tanto de Ave-Maria - mas não agora, no meio da ação (In Medias Res) mas a seguir, só pelo fato de ter se lembrado dessas orações afirma: "Consider them said, he thought. I'll say them later." O tempo necessário para dizer tantas orações é resumido, transformado sinteticamente na simples ação de lembrar. O momento de ação exige rapidez, pensamento sintético, o tempo se comprime ou se expande conforme a necessidade perceptiva.

O mar, aqui, é a fronteira do visível e do invisível, mas também, o espaçotempo das ações de Santiago. Espaço e tempo indissociáveis, que se expressa nos círculos do peixe ao redor do barco, nos movimentos da linha.

Em Os Velhos Marinheiros, quando se apresenta a verdade sobre a forma como Vasco Moscoso de Aragão obteve o título de "Capitão-de-longo-curso", graças ao auxílio generoso de seu amigo Georges; temos também a demonstração de como esse título veio se tornando para Vasco em uma transformação de suas aspirações e de sua personalidade. Descobrimos de onde viera o nome "Benedict" - o famoso barco pelo qual viajara pelo mundo e passara

${ }^{21}$ Op.cit., p. 85-86 
por tantas aventuras, conforme suas narrativas fantasiosas:

Enriqueceu-se de muito seu museu marítimo quando nas costas da Bahia, próximo à capital, naufragou um barco inglês. Foram os objetos à leilão, em hasta pública, e o maior lançador foi o comandante Vasco Moscoso de Aragão. Arrematou a roda do leme, uma preciosa luneta, cronômetros, agulhas magnéticas, anemômetros, higrômetros, o cronógrafo de bordo, uma escada de cordas, sem falar em duas caixas de uísque para oferecer aos amigos.

Não iria mais perder aquela mania de comprar instrumentos náuticos. Terminaria, vários anos depois, por adquirir um telescópio a um aventureiro alemão de passagem pela cidade. Tentara o germânico explorar o objeto na via pública, cobrando um mil-réis de cada cliente interessado em olhar o céu de perto, aproximar a lua e as estrelas. Fracassada a tentativa, conta de pensão a pagar, foi o telescópio para a casa da rua dos Barris, de onde aliás projetava o comandante mudar-se. A sua peça predileta, na coleção a crescer, era a miniatura de um navio, o 'Benedict', de meio metro, reproduzindo em seus mínimos detalhes um barco de passageiros, colocada dentro de uma caixa de vidro. Fora um presente de Jerônimo, no aniversário de Vasco. O jornalista descobrira aquilo no porão do Palácio, a caixa coberta de poeira, jogada num canto como coisa imprestável. Vasco delirou, não tinha palavras para agradecer. [grifos nossos]-(AMADO, 1979)22.

O título do episódio é "De como se constrói um Velho Marinheiro, sem navio e sem navegação", ironia para demonstrar tanto a questão do apadrinhamento, da facilidade com que na obtenção de títulos no Brasil pode ser por meios escusos; mas também para especificamente o narrador nos oferece o processo imaginativo que se desenvolve na consciência de Vasco, de como ele assume a personalidade fictícia que desenvolve de homem do mar.

Vasco torna-se um aficcionado de produtos e materiais náuticos, a expressão "museu marítimo" conota um lugar onde se guardam coisas do passado da navegação, forma simbólica, portanto, de substituir um passado que, em verdade, o personagem não teve. A "roda do leme" e a "preciosa luneta" entre os objetos comprados assumem papel especial. O leme é a direção, mas aqui é a direção das aventuras imaginadas a partir de então, ao passo que a luneta é o modo de aumentar, hiperbolizar suas façanhas. Vasco desenvolve uma "mania" marítima. O telescópio que muita atenção causará em Periperi foi comparado a um aventureiro alemão, e mais que a luneta, indicará agora um aumento da hiperbolização de seu desejo de ser o verdadeiro "capitão-de-longocurso".

Porém, a "peça predileta" é uma miniatura de navio, de meio metro, o "Benedict". Eis o barco que povoará sua imaginação, e por meio dela, o exagerará ao tamanho de um grande navio, pelo qual, se transportará em sonhos a todos os portos do mundo, a todos os oceanos e mares. Lá encontrará uma

22 Op.cit., p. 99 
Dorothy inventada, diferente da real; lá conhecerá outros marinheiros, de lá, vem parte da razão do nome do romance de Jorge Amado, já que "Velhos Marinheiros" é uma expressão no plural. A posse do pequeno "Benedict" será o objeto que psicologicamente o levará a um estado de imaginação para além da razão, o delírio, o onírico.

Já na parte final de Os Velhos Marinheiros, Vasco Moscoso passara por uma prova de suas habilidades náuticas inexistentes. No desembarque do Ita em Belém ordenara, pressionado pelas cobranças do Imediato e dos oficias de bordo, ordenara intuitivamente que o navio baixasse todas as âncoras e fosse preso com todas as amarras. Ordem cumprida sobre risos dos marinheiros, pois tal ordem só se justificaria se se esperasse um maremoto, um tufão, ou um tsunami, mas o clima era tranquilo, sereno e agradável. Aqui se expõe a antítese tempestade / calmaria, e as ordens dadas por Vasco entram em conflito com a análise que os marinheiros fizeram do tempo naquele momento. Dera ordem sem qualquer conhecimento do assunto e escolhera a mais absurda, a mais hiperbólica. Porém, contrariando as previsões, durante a noite, houve uma completa e inesperada mudança de tempo, surgindo uma tempestade que avassalara a cidade e o porto, de sorte que o único navio a se salvar fora o Ita.

Dos quadrantes do mundo vinham num tufão de vingança, dispostos a tudo destruir para salvar o sonho. Veio o ardente Simum com o fogo do deserto, levantando as areias como espantosa muralha. As Monções chegaram do Oceano Índico, por onde tanto navegara o Comandante, vinham em cerrado grupo e arrancavam as casas de seus alicerces, revolteando-as no ar como folhas mortas de árvores. Negro, a assoviar uma canção de morte, Harmatã chegou da África, em rodopios, e desamarrou paquetes, atirando-os contra o cais, rompendo-lhes os mastros e os bueiros. Os ventos Alísios naufragaram barcos, veleiros e jangadas. O Mistral tomou do iate vindo da Guiana Francesa, e numa brincadeira macabra, colocou-o de volta a navegar, rasgou-lhe as velas, arrancou-lhe o leme, arremessando-o para os lados de Marajó, onde as espantadas tartarugas invadiam aldeias. $\mathrm{O}$ frio da morte a pairar sobre a cidade, veio das estepes da Sibéria nas asas brancas dos ventos do inverno glacial. Vinham de longe, traziam meia hora de atraso, mas quando chegaram foi o fim do mundo. Os ventos do Nordeste, o Terral e o Aracati, ocuparam-se do barco inglês e do navio do Lloyd, desamarrando-os de suas insuficientes amarras, batendo um contra o outro num rumor de cascos rotos. O vento Aracati jogou o navio do Lloyd mar a fora, sem mastros, cobertas, tombadilho. $\mathrm{O}$ Terral, nacionalista apaixonado, demorou-se a maltratar o cargueiro inglês, passando sua língua de faca afiada pela garganta dos loiros marinheiros, sua língua de morte nordestina. Terral naufragou o cargueiro perto do cais, num torvelinho, para que ali ficasse plantado como lembrança e advertência. Com os ventos, chegaram as chuvas vindas dali mesmo de perto, da linha do equador onde dormiam nas florestas úmidas, trazendo toda as águas estagnadas da maleita, do tifo, da bexiga negra. Vieram e transformaram a cidade em milhares de rios, riachos, ribeirões e córregos. O rio Amazonas começou a inchar, a 
comer terra com seus dentes ávidos de água, a fabricar ilhas e cadáveres. A pororoca tanto ampliou seu grito que ele mediu quilômetros de pavoroso som e foi ouvido nas costas da África, na cidade de Dakar e em perdidos povoados onde trêmulos selvagens reconheceram o grito de guerra de Xangô. [grifos nossos] - (AMADO, 1979)23

Jorge Amado lista ventos de várias partes do mundo, mitológicos ou reais (Simum, Monções, Negro, Alísios, Mistral, ventos da Sibéria, Terral, Aracati) todos agindo de forma exageradamente espantosa, assim como a hipérbole hiperbórea dos ventos da Sibéria atracando em Belém. Depois a chuva colossal, a enchente enorme do Amazonas, cuja pororoca chegou a Dakar e por fim, a citação a Xangô. A hipérbole que caracterizava as narrativas fantasiosas do falso capitão-de-longo-curso agora se transformava em energia que fomentava a descrição de inesperada tempestade. Assim, Vasco Moscoso foi levado à condição de herói e capitão conhecedor das surpresas dos oceanos. Mas, ao longo do livro, a presença do oceano é sempre sutil. Em praticamente toda a viagem, o mar se apresenta como pano de fundo, leve, quase despercebido para a narrativa. No navio, as conversas e discussões, os jantares, os namoros, tudo se desenvolve por personagens que estão indiferentes ao mar. Mas as descrições que faz das personagens femininas e o modo como percebe a realidade estão repletos de imagens marítimas: Clotilde, a deusa do mar; Moema, a mameluca, por exemplo. O mar é a metáfora da vida imaginária de Vasco Moscoso, e é no mar-real que terá que pôr à prova o impasse entre realidade e ficção. Em alguns breves momentos, se narra a conversa de marinheiros notando a falta de conhecimento de Vasco para as coisas do mar, de forma irônica. Mas é no final, quando tudo parece ter levado o protagonista a um fim melancólico, inclusive com a fuga de Clotilde, as forças da natureza deflagram a tempestade colossal que recupera o destino do personagem para o âmbito da comédia, tom que caracteriza a obra.

Em O Velho e o Mar, de Hemingway, o personagem principal, Santiago, é um pescador. Seu relacionamento com o mar é o que define seu mundo e sua personalidade. Em Os Velhos Marinheiros, Vasco Moscoso é um falso capitão, levado à condição de comandante efetivo de um navio por circunstâncias irônicas do destino; o mar é para ele um estranho, que admira, mas desconhece na intimidade. Ambos são velhos, lutando com o passado, seja o real de Santiago, seja o fabuloso de Vasco. Ambos conseguem, apesar de todas as expectativas contrárias, recuperar seu prestígio social, seu respeito junto às comunidades em que vivem. Se no tom dramático e trágico que determina o livro de Hemingway, Santiago é relacionado simbolicamente, seja por intermédio do peixe, ou por ele mesmo, com a figura de Cristo; Vasco Moscoso de Aragão é o falso profeta - vivendo uma tragicomédia - cujas profecias levam

${ }^{23}$ Op.cit., p. 162 
muitos a acreditar nas suas falácias, contando, no mais das vezes, com o acaso ou para dar crédito ao seu discurso. Jorge Amado, assim, compõe uma obra que pelas suas ironias e hipérboles, nos leva a compor um panorama engraçado, mas profundamente crítico da sociedade ali representada.

O mar em O Velho e o Mar é marcado pelas dicotomias visível / invisível, passado / presente, superfície / profundezas, movimento / inércia; em Os Velhos Marinheiros as dicotomias são passado / presente, terra / mar, tempestade / calmaria e real / fictício. Em O Velho e o Mar, as águas funcionam como símbolo e como metáfora. Em Os Velhos Marinheiros, as águas se transformam na hipérbole da imaginação. A hipérbole em Hemingway é seu peixe, no entanto, hipérbole devorada por tubarões, que só restam os ossos para confirmação de sua veracidade, a linguagem desvelada de suas fantasias e figuras, a prova descarnada dos fatos, a ironia trágica. Em Jorge Amado, a tempestade final é a ironia satírica do destino.

Recebido em 18/11/2016 Aprovado em 11/10/2017 